\title{
ECONOMIC ESSENCE OF MODERN INVESTMENT PROCESSES IN THE GRAIN PROCESSING INDUSTRY
}

\author{
Inna KANASHKINA', \\ Odessa National Academy of Food Technologies, Ukraine
}

\begin{abstract}
The subject of the research is theoretical and methodological bases of formation of effective investment in priorities feed processing industry in Ukraine. The object of research is the investment process in feed processing Ukrainian industry, the main direction and the way to increase the efficiency of the investment process in the industry. The aim is to develop an integrated approach to the study of the economic substance of investments to improve the methods to determine their effectiveness, the study of factors of investment environment, study methodology for determining business risk, development of proposals of the priority areas of investing in feed processing industry, the formation of effective investment strategies for its development in the conditions of market transformation. Methods. We used the following methods: dialectical, abstract logic, Economics and Statistics and the systemic-functional methods of knowledge of economic processes. The dialectical method has allowed the author to analyze the development of research in the last five years, identified reserves and propose ways for its further development. Abstract-logical method of waste classification of the factors influencing the efficiency of the investment process in the industry, the methodological approaches to the formation of the components of the conceptual apparatus studied category. Economic-statistical method used in the study and synthesis of trends and patterns of the dynamics of the industry at the present stage. Systemic-functional method allowed to generalize the theoretical and methodological foundations of development effectiveness feed processing industry. The study also used methods: a comparative analysis - for comparing actual data reporting and previous years; model approach - to determine the entrepreneurial risk in the enterprises of the industry; expert assessments and cost approaches to identify key trends and ways to improve the country's industrial development feed processing industry in the transformation of the economy. Results. Based on the analysis of modern approaches to conditions of increased in-vestment and innovation, continuous improvement of its effectiveness concluded that the creation of fair competition. Civilized competitive environment ensures that each share of investment in innovation combined with a positive effect - increases the number of jobs and the amount of product reduces the cost per unit of output. Significant investment resources for the industry can be attracted by privatization, provided that it will be transparent and competitive. To attract investment in such an important sector for Ukraine, it is necessary to understand and improve the motivation of investors, taking into account the European integration process: the main promising markets for products and services; favorable geographic location of investment targets; increase their competitiveness through the organization of production on the territory of a party that receives the in-vestment; low labor costs in its qualifications.
\end{abstract}

Key words: investment, investment efficiency, investment potential.

JEL Classification: O31, P47, Q13, Q14

\section{1. Введение}

В митературе существуют разные понятие инвестиций, инвестиционной Аеятельности, инвесторов и Ар. Но частое упоминание понятия теряет его сущность. Поэтому, Аля решения проблем, которые связаны с финансированием инвестиционной деятельности преАприятий как способа реализации конкурентных экономических задач, нужно чётко определится с сущностью Аанных понятий.

\section{2. Инвестиции и инвестиционный процесс на преАприятиях Аанной отросли}

Понятие «инвестиции» имеет чётко значение с юриАической точки зрения. Закон Украины «Про инвестиционную Аеятельность» определяет инвестиции как все виды имущественных и интемлектуальных ценностей, вложенных в объекты преАпринимательской и Аругих видов Аеятельности, в результате каких созАается прибыль (АохоА) ими

\footnotetext{
Corresponding author

${ }^{1}$ Department of Accounting and Audit, Odessa National Academy of Food Technologies.

E-mail: inna.kanashkina@mail.ru
} 
Аостигается социамьный эффект (Constitution of Ukraine, 1996).

Категории «производство» и «инвестиции» тесно связаны межАу собой. При этом категория «произвоАство» явмяется шире от категории «инвестиции», так как она вкмючает последнюю в виде важнейшего фактора расширения и обновления производства.

Особенность категории «инвестиции» заключается в том, что как сами инвестиции, так и продукция и прибыль, получаемые от них, реализуются только в Аолгосрочном временном интервале. Считаем необходимым ввести еще одно уточнение: инвестиции - это отложенное потребление. Это приводит к необходимости учета в оценке их эффективности: во-первых, фактора времени, во-вторых, фактора вероятности рисков. Это вызывает необходимость разработки в некоторой степени самостоятельных показателей и методов оценки экономической эффективности инвестиций. При этом в странах с развитой рыночной экономикой на уровне государства не принимают мюбые официальные, Аирективные метоАики оценки эффективности инвестиций: кажАая корпорация, фирма, преАприниматель, банк, креАитор используют показатели и методы, которые соответствуют их целям.

Предложенное нами определение инвестиций имеет некоторые особенности:

- В отличие от развитой рыночной экономики в перехоАных условиях наряду с инвестициями, ради получения прибыли, особое значение имеют вложения в развитие производственной, социальной и научно - технической инфраструктуры, рассчитаны не на непосреАственную прибыль, а на перспективный социальный, экологический и структурной эффект;

- В переходной экономике наряду с инвестиционными проектами негосударственных инвестор особое значение имеют инвестиционные программы - совокупность взаимосвязанных проектов развития отрасли, в финансировании которых участвуют государство, местные органы вцасти, межАународные некоммерческие организации и фонды;

- В отличие от капитальных вложений, имеется в виду три формы вложений - финансовая (национальная валюта, иностранные валюты, миквидные ценные бумаги), материальная (земельные участки, зАания, сооружения, природные ресурсы и т.А.) и нематериальная (патенты, промышленные образцы, товарные знаки, «ноу-хау», промышиенные права и т.А.);

- КАючевые слова определения соответствуют действующей законодательной базе.

С точки зрения направленности инвестиции можно разделить на следующие виды:

- Инвестиции, осуществленные при созАании ими покупке преАприятия;

- Инвестиции на расширение (экстенсивные инвестиции), направляемые на увеличение производственного потенциака;
- Инвестиции на рационализацию, направляемые на модернизацию или реконструкцию технологического оборудования или процессов;

- Инвестиции на Аиверсификацию, связанные с изменением номенклатуры продукции, созданием новых видов продукции и организацией новых рынков сбыта; - Инвестиции в научные исследования, связанные с исследованиями и разработками, подготовкой каАров, рекламой, охраной окружающей среАы;

- Инвестиции, которые обеспечивают использование заказу государственного или иного крупного заказчика; - Инвестиции, которые направцяются на удовлетворение требований государственных органов;

- Инвестиции, которые направляются на пополнение оборотных активов.

ВслеАствие того, что инвестициями считают среАства, за счет которых формируется преАприятие, они становятся неотъемлемыми от самого процесса их вложения, который и называют инвестиционным процессом или инвестиционной Аеятельностью. ПоА инвестиционным процессом понимается процесс вложения инвестиций - выбор наилучшей амьтернативы, проектирование, создание и эксплуатация объекта инвестирования (Financial Management, 1998). Субъектами инвестиционной деятельности являются юридические и физические мица, которые принимают решения и осуществляют вложения собственных, заемных или привлеченных среАств в форме инвестиций в инвестиционный проект и обеспечивают их целевое использование. В качестве инвесторов могут выступать органы, уполномоченные управлять государственным и муниципальным имуществом или имущественными правами; гражАане, преАприятия, преАпринимательские объединения и Аругие юридические мица; иностранные юридические и физические мица, государства и международные организации (The Law of Ukraine «On investment activity», 1991; 1998).

Принципиально важной сутью есть, вложения в понятие «инвестиционный комплекс». Попробуем подробнее раскрыть ее. Инвестиционный комплекс принято трактовать как совокупность отраслей экономики, обеспечивающих ее потребность в основных фонАах. ГАавной отраслью инвестиционного комплекса слеАует считать строительство, потому что продукцией капитального строительства явцяется, подготовмены к введению в Аействие основные фонды и производственные мощности. Вокруг строительства формируется компиекс сопряженных отраслей и производств, которые охватывают главные обрабатывающие предприятия (The Law of Ukraine «On Leasing», 1998; 1999).

Основными факторами воспроизводства инвестиционного комплекса есть ресурсы на-накопление и инновационное обеспечение. ПодАержка на определенном уровне источников накопления служит основным условием функционирования и развития всех факторов экономики. В свою очереАь, источники накопления нормально воспроизвоАятся при соблюАении обязательного 
условия: рост масштабов производства Аолжен сопровожАаться относительной экономией ресурсов, совершенствованием и повышения эффективности технических систем. Если инвестиционный комплекс, материализуя финансовые ресурсы накопления в средства труда, обеспечивает в процессе нового строительства и модернизации действующих предприятий Аостижения этих результатов, он наряду с Аругими секторами экономики зарабатывает среАства Аля расширенного воспроизвоАства. Таким образом, саморазвитие инвестиционного комплекса возможен только при наличии мощной инновационной сферы, постоянно обновмяет его техникой и технологией все новых и новых поколений. Если же рост показателей новой техники оказываются недостаточными, чтобы компенсировать объективную тенденцию к росту издержек производства в целом, то Аля выживания инвестиционного комплекса не остается Аругого выбора, кроме опережающего, по сравнению со среАними по народному хозяйству темпами повышения цен на свою продукцию. Именно последний вариант и получил законченное воплощение в послеАние годы функционирования планово распределительной экономики.

Инвестиционный процесс определяется в китературе (Gitman L., Junks M., 1997) как механизм сведения вместе тех, кто предкагает деньги (имеет временно свободные средства), с теми, кто предъявмяет спрос (нужаается в них). Обе стороны обычно встречаются в финансовых институтах или на финансовом рынке. ИногАа, в частности при саелках с имущественными ценностями (например, с неАвижимостью), продавцы и покупатели вступают в соглашение напрямую. Финансовые институты - организации (банки), которые принимают вклады и дают привлеченные деньги в креАит, или инвестируют в Аругих формах. Финансовые рынки - это механизм, который Аля заключения сАелок сводит вместе тех, кто предлагает финансовые ресурсы, с теми, кто их ищет, как правимо, с помощью посреАников - финансовых рынков: рынок акций, рынок облигаций. Их общей особенностью явмяется то, что цена

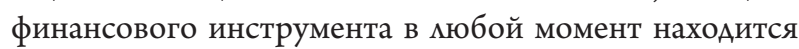
в равновесии спроса и преАложения.

Таким образом, отличительная черта инвестиционной сферы в промышленно развитых странах состоит в том, что формирование инвестиционной стратегии происходит на уровне корпораций. Механизм принятия и реализации инвестиционных решений напрямую связан с финансовой ответственностью самих преАприятий. Это обстоятельство превращает инвестиционную Аеятельность в инструмент реализации нововведений, с которых начинается разработка проектов на альтернативной основе в конкурентной рыночной среАе.

Инвестиционную политику корпораций главных капиталистических стран в послеАние Аесятилетия определяли поиски принципиально иных технологических решений для выхода из кризиса, а не привлечения Аополнительных ресурсов. Если не вдаваться в рассмотрение этой проблемы, Аиссертанту хотелось бы подчеркнуть, что ограничение притока капитальных ресурсов при повышении их качества, эффективности их распределения и использования - важнейшая особенность современных инвестиционных процессов в развитых странах.

Аля оценки возможных объемов и приоритетных направлений в инвестировании особое значение имеет точное определение состояния инвестиционного потенциала страны или региона. А^я этого используем анализ инвестиционного климата. Инвестиционный кАимат - это совокупность политических, социально-экономических, финансовых, социально-культурных, организационно-правовых и географических факторов, характеризующих страну, регион с точки зрения преимущества и эффективности размещения капитаца (Karandakova I., 1998; Matviychyk G., 1999).

Но, поскольку инвестиции региона или государства формируются по инвестициям отдельных преАприятий, зАесь не рассмотрены факторов инвестиционного процесса. Поэтому мы преАлагаем ввести понятие «инвестиционная среда», которое будет вкцючать как систему внутренних факторов (субъективных, которые зависят от организации производства и менеАжмента предприятия) и внешних (объективных, которые формирует естественное, политически-экономическом, научно-техническом, Аемографическое среды страны). ПоА инвестиционной средой понимают совокупность Аействующих субъектов и сил, влияющих на изменение эффективности инвестиционной Аеятельности.

Наряау с понятием «инвестиционный климат» мировая практика знает и термин «инвестиционный риск», который указывает на степень отталкивания инвесторов от вложения среАств в Аанную страну или регион. ИногАа инвестиционный риск, не имея структурных различий, служит показателем, обратным инвестиционному климату. ИногАа он включает в себя только негативные факторы инвестиционного климата, отталкивающих потенциального инвестора.

Термин «потенциац» (от матинского слова potentia) обычно трактуется как «сила», «мощность». Этот термин употребляется Аля обозначения среАств, запасов и источников, имеющихся в наличии, которые могут быть использованы Аля Аостижения определенной цели, решения определенной проблемы, а также возможностей отАельного мица, общества, государства в соответствующей отрасли.

Понятие потенциала тесно связано со структурой цемей и опредемяется как «совокупность возможностей» преАприятия. ПоА потенциалом преАприятия (отрасли) принято понимать совокупность показателей или факторов, характеризующих его (ее) силу, источники, возможности, среАства, способность, ресурсы, которые могут быть использованы в экономической Аеятельности (A large economic dictionary, 2002). Соглашаясь в принципе с вышеприведенным подходом трактовки понятия «потенциам», по нашему мнению, неправомерно сужать его к характеристикам только 
производственных резервов. В работе рассматривается инвестиционный потенциал в контексте резервов всех направлений Аеятельности преАприятия (отрасли).

Под инвестиционным потенциалом будем понимать интегрированную совокупность всех имеющихся материальных и нематериальных активов, используемых Аля осуществления инвестиционной Аеятельности. В рыночных условиях к инвестиционному потенциалу могут быть отнесены все ресурсы, которые обеспечивают Аостижение конкурентных преимуществ преАприятия путем внедрения инвестиций (рис. 1).

Учитывая стратегический характер решений, инвестиционный потенциа важно оценивать с учетом особенностей внешней среды и выявлением в нем стратегических возможностей исследуемого объекта. По результатам мониторинга инвестиционного потенциала преАприятия (отрасли) можно разработать приемлемую стратегию инвестиционного развития, с помощью которой при реализации инвестиционного потенциала достигаются цели и миссия объекта.

\section{3. Оценка инвестиционного потенциама преАприятий Аанной отрасли}

Обеспечение устойчивого экономического роста мюбого преАприятия требует, среди прочего, постоянного осуществления инвестиций в его развитие. В частности это касается отечественного аграрного сектору, большинство преАприятий которого требует существенного технического перевооружение на базе внедрения новых технологий и замены устаревших основных среАств.
Вместе с тем, ограниченность объемов собственных инвестиционных ресурсов и затрудненность доступа к кредитным источникам финансирования, обусловливает необходимость выбора приоритетных направлений инвестирования развития аграрных предприятий и обоснование рациональных размеров инвестиций по кажАому инвестиционном проекте (Hryshko V., 2010).

В то же время, чтобы быть привлекательным Аля потенциальных инвесторов, преА-приятие Аолжно характеризоваться наличием внутренних и внешних возможностей привлекать и использовать инвестиционные ресурсы Аля своего развития и обеспечивать максимизацию экономического эффекта субъектам инвестирования за минимального инвестиционного риска (Boyarko I., 2008). То есть инвестиционный потенциал определяет совокупную способность преАприятия осуществлять инвестиционную Аеятельность, а эффективность этой деятельности Аетерминируется уровнем и объемом использование этого потенциала (Berezhnaya I., 2010).

Инвестиционная привлекательность аграрного преАприятия характеризуется совокупностью показатемей его финансово - экономического состояния, на основе анализа которых потенциальный инвестор может принять управменческое решение по целесообразности вложения свободных среАств в развитие этого преАприятия без значительного риска их потери или неполучения ожидаемого дохода на инвестированный капитал (Mordvintseva T., 2010). Актуацьность оценки уровня инвестиционной привлекательности преАприятий определяется рядом условий, важнейшим среАи

\begin{tabular}{|c|c|c|c|}
\hline \multicolumn{2}{|c|}{$\begin{array}{c}\text { Инвестиционный потенциал } \\
\text { материальных ресурсов }\end{array}$} & \multicolumn{2}{|c|}{ Интеммектуальный потенциал } \\
\hline Основных среАств & $\begin{array}{l}\text { Основное и вспомогательное } \\
\text { оборудование; } \\
\text { Компьютерный парк; Транспортные } \\
\text { средства; ЗАания и сооружения, } \\
\text { переАаточные устройства; Библиотечный } \\
\text { фонА. }\end{array}$ & $\begin{array}{l}\text { Нематериальных } \\
\text { активов }\end{array}$ & $\begin{array}{l}\text { Патент; } \\
\text { Авторское право, права на дизайн; } \\
\text { Производственные секреты (ноу-хау); } \\
\text { Товарные знаки, знаки обслуживания. }\end{array}$ \\
\hline Оборотных активов & $\begin{array}{l}\text { Запасы, товары; } \\
\text { Векселя полученные; } \\
\text { Аебиторская задомженность; } \\
\text { Текущие финансовые инвестиции; } \\
\text { Аенежные среАства и их эквиваленты; } \\
\text { Прочие оборотные активы. }\end{array}$ & $\begin{array}{l}\text { Маркетинговых } \\
\text { ресурсов }\end{array}$ & $\begin{array}{l}\text { Маркетинговый опыт; } \\
\text { Репутация преАприятия; } \\
\text { Кмиентурная база; } \\
\text { Приверженность потребителей; } \\
\text { Портфемь заказов; } \\
\text { Франшизные соглашения; } \\
\text { Аицензионные соглашения. }\end{array}$ \\
\hline Земии & $\begin{array}{l}\text { С учетом ресурсов, которые могут } \\
\text { Аобираться }\end{array}$ & $\begin{array}{l}\text { Управленческо- } \\
\text { инфраструктурньх } \\
\text { ресурсов }\end{array}$ & $\begin{array}{l}\text { Организационная структура; } \\
\text { Концепции управления; } \\
\text { Коммуникационные сети; } \\
\text { Информационные технологии; } \\
\text { Партнерские отношения с } \\
\text { поставщиками и посредниками }\end{array}$ \\
\hline Филиалов & $\begin{array}{l}\text { Основных среАств; } \\
\text { Оборотных активов; } \\
\text { Земли }\end{array}$ & Трудовых ресурсов & $\begin{array}{l}\text { Образование; } \\
\text { Уровень квалификации; } \\
\text { Профессиональные способности; } \\
\text { Профессиональные навыки; } \\
\text { Психометрические характеристики }\end{array}$ \\
\hline
\end{tabular}

Рис. 1. Потенциахообразовывающие составмяющие инвестиционного потенциала промышиенного преАприятия 
которых явцяется интенсивность изменения факторов внешней инвестиционной среды, а именно высокая Аинамика основных макроэкономических показателей, связанных с инвестиционной активностью преАприятий, темпы технологического прогресса; частые колебания конъюнктуры инвестиционного рынка; непостоянство государственной инвестиционной политики и форм регулирования инвестиционной деятельности.

ИсслеАуя инвестиционную привлекательность субъектов хозяйствования, целесообразно рассматривать ее с позиции обеспечения возможности реализации инвестиционного потенциала преАприятия. Инвестиционная привлекательность и инвестиционный потенциа явмяются своеобразными формами взаимодействия инвестиционного интереса и инвестиционной потребности. Если учесть, что инвестиционные потребности и инвестиционный интерес находятся у определенном противоречии (жекание получить существенные Аоходы при минимальных вложениях), то самое взаимоАействие межАу инвестиционной привлекательностью и инвестиционным потенциалом раскрывает внутренний механизм осуществления инвестиционной деятельности как Авижущей силы развития производства.

При этом инвестиционная привлекательность является общей характеристикой преимуществ и неАостатков инвестирования отдельных направлений и объектов с позиции конкретного инвестора (Boyarko I., 2008). Также целесообразно выделять понятие инвестиционной привмекательности группы преАприятий, которая преАставляет собой среАневзвешенную оценку уровня инвестиционной привлекательности преАприятий, входящих в группу, с учетом их относительной величины, масштаба деятельности и степени значимости. Современные методики оценки инвестиционной привлекательности групп преАприятий представлены преимущественно отраслевым анализом или на основе территориальной принадлежности (Zhukov M., 2010).

Основные структурные элементы инвестиционной привлекательности субъектов хозяйствования и их взаимосвязи преАставлены на рис. 2, который объясняет могику аналитических подходов, использованных в Аанной разработке методики оценки инвестиционной привлекательности субъектов хозяйствования.

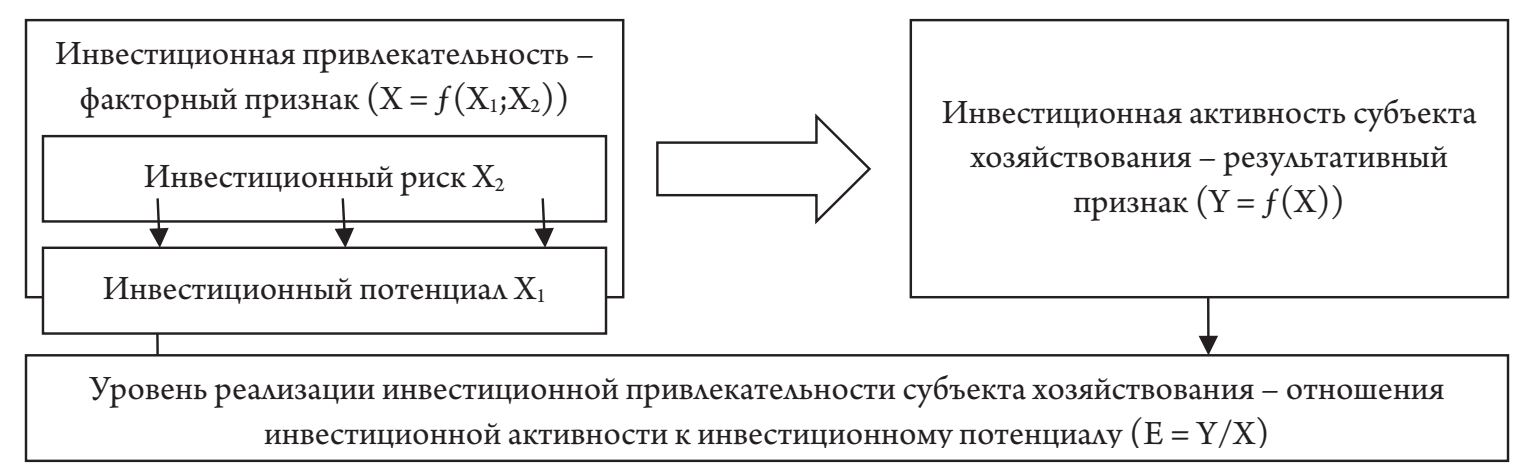

Рис. 2. Механизм взаимодействия инвестиционного потенциама и инвестиционного риска

субъекта хозяйствования (Epifanov A., 2007)
При этом тесно связанными с инвестиционной привлекательностью такие понятия:

1) инвестиционный потенциац субъекта хозяйствования - совокупность финансово - экономических ресурсов, которые могут быть привлечены за счет всех ( внешних и внутренних ) источников финансирования, и факторов, которые создают необходимые условия Аля обеспечения желаемого уровня его инвестиционной активности, оптимального использования этих ресурсов с целью достижения стабильного финансово - экономического функционирования Аанного субъекта хозяйствования и роста эффективности его Аеятельности (Epifanov A., 2007);

2) инвестиционная активность субъекта хозяйствования - интенсивность привлечение долгосрочных инвестиций в капитам преАприятия (Epifanov A., 2007);

3) инвестиционный риск субъекта хозяйствования вероятность неполной реализации инвестиционного потенциала, следствие Аействия объективных неблагоприятных условий инвестиционной деятельности, формирующих вероятность финансовых потерь дохода от инвестиций ими уменьшение капитала (Narolina Y., 2009).

\section{4. Вывод}

В связи с отсутствием четкого формирования понятия «инвестиции» и относительной новизной Аанного срока Аля современной отечественной науки, автором преАлагается альтернативное определение инвестиций как экономических ресурсов, изымаемых из текущего оборота одного субъекта хозяйствования и направцяются на формирование в необоротных и оборотных активов Аругого с целью получения различного рода выгоА.

Таким образом, оценка инвестиционной привцекательности аграрного предприятия явмяется необхоАимым условием Аля выбора Аальнейшей финансовой стратегии его развития, обоснование целесообразности осуществления капитальных вложений. Рациональные управленческие решения при этом Аомжны быть направмены на повышение качества инвестиционного потенциала преАприятия путем согласования улучшение пропорций межАу его компонентами, Аинамичного и гибкого развития внутренней структуры и усиление проблемной ориентации по системе стратегических цемей развития. 


\section{References}

Constitution of Ukraine (1996). Adopted at the 5th session of the Verkhovna Rada of Ukraine 28.06.1996 p. - K.: Ukrainian Legal Foundation.

The Law of Ukraine «On investment activity» // Details BP Ukraine. - 1991. - № 47; 1998. - № 31.

The Law of Ukraine «On Leasing» // Details BP Ukraine. - 1998. - № 16; 1999. - № 9.

A large economic dictionary (2002) / Ed. A. Azrimana. - 5th ed. ext. And Revised. - M. : Institute of New Economy. $-1280 \mathrm{p}$.

Financial Management (1998): A guide to effective management techniques. - M.: «penalty». 464 p.

Berezhnaya, I. (2010) - theoretic economic approaches to study the content's potential investment / I. Berezhnaya // Countries and regions. Series: Economy and business. - № 6. - P. 258-263.

Boyarko, I. (2008). Evaluation of investment attractiveness of business entities / IM Beau Bright / / Actual problems of economy. - № 7. - P. 90-99.

Hryshko, V. (2010). Patterns of formation of the investment potential of engineering companies / V. Grishko // East. - № 2. - P. 28-32.

Gitman, L., Junks, M. (1997). Investing Basics. Trans. from English. - M .: Case. - 683 p.

Epifanov, A. (2007). credit rating and investment attractiveness entities: monograph / Epifanov AA, NA Dekhtyar, TN Miller et al. / Ed. d. e. n. A. Epifanov. - Sumy: UAB NBU. - 286 p.

Zhukov, M. (2010). Methods of assessing the investment attractiveness of enterprises and enterprise groups / M. Zhukov // Bulletin of the Siberian State Aerospace University. Reshetnev. - № 4. - P. 200-204.

Matviychyk, G. (1999). Do in Ukraine will improve conditions for investment? // Mick economy. Finance. Right. P. 31-32.

Mordvintseva, T. (2010). Methodical approach to the evaluation of investment attractiveness of pi-dpryyemstva / TV / / Mordvintseva countries and regions. Series: Economy and business. - № 6. - P. 286-291.

Narolina, Y. (2009). Investment potential and investment risk as the main components of investment attractiveness of the region / Y. Narolina / / Bulletin of the University of Tambov. Series: Humanities. - V. 80. - № 12. - P 137-143. Karandakova, I. (1998). Forming the investment climate in Ukraine and ways of its improvements forgiveness // Economy. Finance. Right. - № 5. - P. 42-48.

\section{Инна КАНАШКИНА}

\section{ЭКОНОМИЧЕСКАЯ СУЩНОСТЬ СОВРЕМЕННОГО ИНВЕСТИЦИОННОГО ПРОЦЕССА НА ПРЕДПРИЯТИЯХ ЗЕРНОПЕРЕРАБАТЫВАЮЩЕЙ ПРОМЫШЛЕННОСТИ}

Аннотация. Предметом исследования является теоретическая и методологическая основы формирования приоритетов эффективного инвестирования в зерноперерабатывающей промышленности Украины. Объектом исследования является инвестиционый процесс в зерноперерабатывающей промышленности Украины, основные направление и путь повышения эффективности инвестиционного процесса в отрасли. Целью работы является развитие комплексного подхода к исследованию экономической сущности инвестиций, совершенствование методики определения их эффективности, исследование факторов инвестиционной среды, обоснование методики определения предпринимательского риска, разработке предложений из приоритетных направлений инвестирования в зерноперерабатывающей промышленности, формирование эффективной инвестиционной стратегии для ее развития в условиях рыночных трансформаций. Методика. В работе использованы следующие методы: диалектический, абстрактно-логический, экономико-статистический и системно-функциональный методы познания экономических процессов. Диалектический метод позволил автору проанализировать развитие объекта исследования в течение последних пяти лет, выявить резервы и предложить пути его дальнейшего развития. Абстрактно-логическим методом отработанные классификация факторов, влияющих на повышение эффективности развития инвестиционного процесса в отрасли, методические подходы к формированию составляющих понятийного аппарата исследуемой категории. Экономико-статистический метод применялся при изучении и обобщении тенденций и закономерностей динамики развития предприятий отрасли на современном этапе. Системно-функциональный метод позволил обобщить теоретико-методологические основы повышения эффективности развития зерноперерабатывающей промышленности. В исследовании также использовались методы: сравнительного анализа - для сравнения фактических данных отчетного и предыдущих лет; модельного подхода - для определения предпринимательского риска на предприятиях отрасли; экспертных оценок и стоимостных подходов при определении основных направлений и путей повышения эффективности развития зернопереробной промышленности страны в условиях трансформации экономики. 
Vol. 1, 2015

Результаты исследования. На основе анализа современных подходов к условиям активизации инвестиционной и инновационной деятельности, постоянного повышения ее эффективности сделан вывод о создании добросовестной конкуренции. Цивилизованная конкурентная среда способствует тому, что каждая доля инвестиций в сочетании с инновациями дает положительный эффект - увеличивает количество рабочих мест и объём продукции, снижает стоимость единицы продукции. Значительные инвестиционные ресурсы для отрасли могут быть привлечены путем приватизации, при условии, если она станет прозрачной и конкурентной. Для привлечения инвестиций в такую важную для Украины отрасль, необходимо понимать и повышать мотивацию инвесторов с учетом евроинтеграционных процессов: основных перспективных рынков сбыта продукции и услуг; благоприятное географическое положение объектов инвестирования; повышение своей конкурентоспособности путем организации производства на территории стороны, которая принимает инвестиции; низкая стоимость рабочей силы при ее высокой квалификации. 